\title{
A rare cause of thigh pain: Morel-lavallée lesion
}

\author{
Rana Terlemez, Tülay Erçalık, Figen Yllmaz, Hüseyin Bertan, Banu Kuran \\ Department of Physical Medicine and Rehabilitation, Şişli Hamidiye Etfal Training and Research Hospital, İstanbul, Turkey
}

Received: December 12, 2016 Accepted: March 17, 2017 Published online: February 05, 2018

\begin{abstract}
Morel-Lavallée lesion is an unusual clinical entity which was first described by the French surgeon Maurice Morel-Lavallée in 1853. These lesions result from peeling off the surfaces between the fat tissue and the muscular fascia. During this decomposition, the rupture of small vessels may cause an effusion full of necrotic blood, lymph and fat cells. In prolonged cases, these lesions may become increasingly painful, leading to be confused with other diagnosis such as sciatalgia, piriformis syndrome, trochanteric bursitis or soft tissue tumor. Herein, we present a-65-year-old female case who had pain in the right thigh for one year and was referred to our clinic with radicular pain.
\end{abstract}

Keywords: Morel-Lavallée lesion; musculoskeleteal ultrasound; thigh pain.

Morel-Lavallée lesions (MLLs) are sudden separation of the subcutaneous fat from the muscular fascia. These lesions are the result of degradation of the facial interface with subcutaneous fat. The tear of small puncture vessels in this area results in an effusion containing hemolymph and necrotic fat. This type of injury is not very frequent. Publications on this injury in the literature consist of a limited number of case reports and series. Chronic lesions and misdiagnoses are rarer. ${ }^{[1]}$

Morel-Lavallée lesions are often seen in the lateral thigh, commonly in the trochanteric neighborhood. ${ }^{[2]}$ They have also been seen near bony prominences such as lumbar spinous processes, spina scapula, knee and abdominal wall after liposuction. ${ }^{[3-5]}$

Morel-Lavallée lesions usually appear suddenly after an inciting trauma; however, the diagnosis may be delayed in approximately one third of patients. ${ }^{[6]}$ In an acute trauma, MLLs require surgical excision or percutaneous drainage. ${ }^{[7]}$ However, these effusions may be initially missed, which can cause misdiagnosis. ${ }^{[3,7]}$ In chronic cases, these lesions may slowly widen in months and years and may start to be painful and usually mimic other musculoskeletal disorders such as sciatalgia, piriformis syndrome, or trochanteric bursitis.
In the differential diagnosis, soft tissue tumors should be kept in mind, although the characteristics of a MLL are atypical for a tumor. Other diagnoses to be excluded are fat necrosis, sarcoma, hemangioma, and subcutaneous hematoma. The typical location, structure, and healing pattern can help to make correct diagnosis and treatment.

Magnetic resonance imaging (MRI) and ultrasound are valuable modalities for assessment. Sonography can be viably used to analyze and describe liquid accumulations such as MLLs. ${ }^{[8]}$ Chronic MLL is a very rare condition, and there are just few reports in the literature. Herein, we present a 65-year-old woman who was referred to our clinic with radicular pain and was diagnosed with MLL through ultrasound.

\section{CASE REPORT}

A 65 -year-old woman with pain at the right thigh was referred to our clinic from the neurosurgery department with the diagnosis of radiculopathy. The patient complained for pain for one year, particularly during sitting and walking. Her pain became worse about three months. In her medical history, she had decompression surgery for lumbar spinal stenosis 16 months ago. She had three episodes of extreme

Corresponding author: Rana Terlemez, MD. Şişli Hamidiye Etfal Eğitim Araştırma Hastanesi, Fiziksel Tip ve Rehabilitasyon Kliniğí, 34371 Şişli, İstanbul, Turkey. 
sciatica in the course of recent years. She was typically an exceptionally dynamic individual, yet disappointed with her constrained capacity to walk and she had no history of prior trauma.

On physical examination, she had flattened lumbar lordosis with an incision scar. Lumbar extension was mildly limited and painful. The sitting straight leg raising (SLR) test was negative bilaterally. Supine SLR was painful due to the shortened hamstring muscles. Neurological examination included lower extremity strength, and sensory examination findings were normal; however, there was no Achilles reflex on the right side. Also, no atrophy of the lower extremity muscles was seen. The range of motion of the coxofemoral joints were normal and painless; however, she had tenderness and minimal swelling in the posterolateral thigh on palpation. Pain was reported to originate from this area.

Thigh pain of the patient did not resemble with the radicular pattern and did not spread below the knee. There were no accompanying dysesthesia or paresthesia complaints. On physical examination, we found a painful swelling in the posterolateral thigh and we thought that her complaints were not related to radiculopathy.

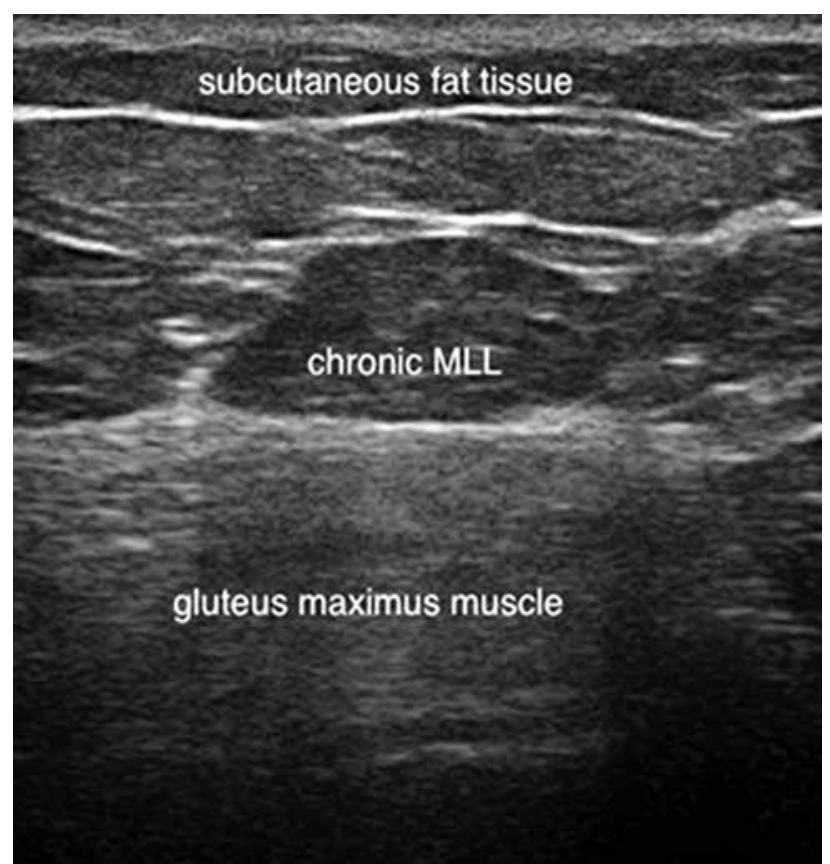

Figure 1. Isoechoic homogeneous collection with a regular margin between the deep fat and overlying fascia without flow on color Doppler imaging consistent with chronic Morel-Lavallée lesion.
Pelvic MRI was done a month ago which yielded normal results. Therefore, the patient underwent ultrasonographic examination for the swollen lesion. An isoechoic homogeneous collection was found with a regular margin between the deep fat and overlying fascia without flow on color Doppler imaging consistent with chronic MLL (Figure 1). She had pain in this area with sonographic palpation. The patient was treated with percutaneous drainage and steroid injection under the guidance of ultrasonography.

\section{DISCUSSION}

Morel-Lavallée lesion, which is also named as Morel-Lavallée seroma, post-traumatic soft tissue cyst, post-traumatic extravasation, or Morel-Lavallée effusion, was first described by a French specialist in $1863{ }^{[9]}$

The injury begins with peeling off subcutaneous tissues away from the muscular fascia, leading to a cavity full of bloody serous liquid. The lesion may regress over time or sustained progression may continue. These lesions are usually seen in hours to days after a sudden trauma. However, the diagnosis may be postponed in around $33 \%$ of the patients, as in our case. Delay in the diagnosis may lead to the improvement of swelling and deformation between the fascia and subcutaneous fat tissue. ${ }^{[4]}$ There are also cases diagnosed after more than 30 years. ${ }^{[2]}$

Localized swelling and pain during palpation is important for the diagnosis in patients with clinical suspicion of MLL. Imaging modalities such as MRI and ultrasonography can be useful. In longstanding cases, pseudocapsule formation may be seen in radiological examinations.

Morel-Lavallée lesions tend to be unilateral. Patients usually suffer from pain, swelling, and tension usually in the lateral thigh accompanied by ecchymosis. The lesion size may be variable and usually have an oval shape, particularly in chronic cases. ${ }^{[10]}$ The Achilles reflex on the right side was absent in our patient. However, the patient underwent surgery for lumbar spinal stenosis 16 months ago and the surgeon noted the absence of the Achilles reflex at that time. Thigh pain of the patient did not fit the radicular pattern and did not spread under the knee. There were no accompanying dysesthetic complaints. On physical examination, we found a painful swollen mass in the posterolateral thigh and we did associate the patient's complaints with radiculopathy. 
On ultrasound, MLL seems anechoic or hypoechoic in acute cases, and over time echogenicity may increase depending on the absorption of liquid fraction. A pseudocapsule may also be seen in different thicknesses. ${ }^{[3]}$ After initiating trauma, the pouch fills with blood and lymph at first. This effusion is, then, replaced by a serosanguineous fluid and may become capsulated. Magnetic resonance imaging is effective in distinguishing MLL from the soft tissue tumors. ${ }^{[2]}$ Whatever the age of MLL, it has a specific location between the fat tissue and muscular fascia. In addition, the chronic lesions usually have a homogeneous pattern with a pseudocapsule on MRI. ${ }^{[8]}$

Hemangioma, hematoma, fat necrosis, and soft tissue tumors should be considered in the differential diagnosis of MLLs. The history of trauma, specific location, and sonographic appearance may lead to correct diagnosis.

There are some different ways to treat MLL. In the acute-onset and oversized MLL, Hak et al. ${ }^{[7]}$ suggested surgical excision to avoid infections. Different strategies include aspiration with or without pressure, applying sclerosing agent or steroid into the lesion. ${ }^{[1]}$ Our case had a good therapeutic response with minimally invasive percutaneous approach and steroid injection with ultrasonography guidance. Surgical excision option should be kept in mind in persistent cases.

In conclusion, chronic MLL is a rare condition. It may be easier to diagnose acute lesions with clinical and radiological evidence. Although acute MLL has a tendency to have heterogeneous and hypoechoic pattern in sonographic examination; chronic MLL seems more homogeneous and well-shaped. Pelvic MRI can be misleading for MLL, if the fat tissue is neglected during scan, as in our case. Ultrasound can be a practical guide for the correct diagnosis in patients with atypical unilateral thigh pain.

\section{Declaration of conflicting interests}

The authors declared no conflicts of interest with respect to the authorship and/or publication of this article.

\section{Funding}

The authors received no financial support for the research and/or authorship of this article.

\section{REFERENCES}

1. Singhal A, Dharmshaktu GS, Singh P. Managing neglected Morel-Lavallée lesion of thigh in a limited resource environment: a case report and review of literature. Int J Sci Rep 2015;2:148-50.

2. Mellado JM, Bencardino JT. Morel-Lavallée lesion: review with emphasis on MR imaging. Magn Reson Imaging Clin N Am 2005;13:775-82.

3. Parra JA, Fernandez MA, Encinas B, Rico M. Morel-Lavallée effusions in the thigh. Skeletal Radiol 1997;26:239-41.

4. Tejwani SG, Cohen SB, Bradley JP. Management of MorelLavallee lesion of the knee: twenty-seven cases in the national football league. Am J Sports Med 2007;35:1162-7.

5. Scaranelo AM, Davanço RA. Pseudocyst formation after abdominal liposuction-extravasations of Morel-Lavallée on MR images. Br J Plast Surg 2005;58:849-51.

6. Hudson DA, Knottenbelt JD, Krige JE. Closed degloving injuries: results following conservative surgery. Plast Reconstr Surg 1992;89:853-5.

7. Hak DJ, Olson SA, Matta JM. Diagnosis and management of closed internal degloving injuries associated with pelvic and acetabular fractures: the Morel-Lavallée lesion. J Trauma 1997;42:1046-51.

8. Neal C, Jacobson JA, Brandon C, Kalume-Brigido M, Morag Y, Girish G. Sonography of Morel-Lavallee lesions. J Ultrasound Med 2008;27:1077-81.

9. Mellado JM, Pérez del Palomar L, Díaz L, Ramos A, Saurí A. Long-standing Morel-Lavallée lesions of the trochanteric region and proximal thigh: MRI features in five patients. AJR Am J Roentgenol 2004;182:1289-94.

10. Gummalla KM, George M, Dutta R. Morel-Lavallee lesion: case report of a rare extensive degloving soft tissue injury. Ulus Travma Acil Cerrahi Derg 2014;20:63-5.

11. Kottmeier SA, Wilson SC, Born CT, Hanks GA, Iannacone WM, DeLong WG. Surgical management of soft tissue lesions associated with pelvic ring injury. Clin Orthop Relat Res 1996;329:46-53. 